\title{
Henciclopedia, Humanidades y una campaña contra la analfabetización
}

\section{del Uruguay}

DOI: $10.46932 / \mathrm{sfjdv2n1-026}$

Received in: November 1st, 2020

Accepted in: December 30th, 2020

\section{Stephen Gregory}

Higher Ed.: Ph.D

Institution: Honorary Research Fellow, School of Humanities and Languages, University of New

South Wales

Full address: República de El Salvador 3324bis, 11600 Montevideo, Uruguay

E-mail: swgg29@yahoo.com.au

\begin{abstract}
The author examines the campaign in two online, free-access Uruguayan publications, Henciclopedia and Interruptor, for the reassertion and renovation of the Humanities in the age of Tweets and Messaging under an aggressive neoliberal capitalism that threatens to commercialize and quantify all forms of knowledge acquisition and transmission. The group responsible for these digital publications were responding to the war waged against the Humanities in Universities and High-schools by reductionist State education policies that emphasized only utilitarian criteria to establish priorities in secondary and tertiary education. The article also examines the debate among different members of the group between traditional and poststructuralist accounts of the continuing value of writing and reading literature and their relationship to changing approaches to the notion of "Truth".
\end{abstract}

KEYWORDS: Humanities, literature, reading, writing, education, deconstruction, technology, commercialization, knowledge.

\section{INTRODUCCIÓN: ¿QUÉ HENCICLOPEDIA Y A QUÉ SE DEDICA?}

La portada de Henclopedia incluye un elogio del sitio como el mejor website cultural de América Latina. No puedo saber si es así aunque el sitio bien merece un análisis bastante más completo que el que sigue. Lo que el lector va a encontrar aquí es parte de la sección sobre Henciclopedia de un texto más largo sobre la defensa de las Humanidades y su rol en la educación superior uruguaya como parte del debate acérrimo sobre la situación actual de la educación pública en Uruguay y el papel que debe asumir en ella la enseñanza de la alfabetización básica y avanzada en un contexto dominado por las nuevas tecnologías digitales y virtuales ligadas a una economía globalizada de impronta neoliberal. El capítulo entero sobre las Humanidades funcionará como estudio de caso en un volumen dedicado al análisis del rol de los intelectuales bajo los tres gobiernos del Frente Amplio, coalición de centro-izquierda que gobernó el Uruguay entre 2005 y 2020. 
El primer volumen de la colección lengua nueva (escrito así) de H editores, el brazo editorial del sitio de Internet Henciclopedia, publicado en marzo de 2016, se titula así: Humanidades milenio 3 y lleva como subtítulo La naturaleza y el futuro de los saberes humanísticos en la era de la virtualidad. Ya hace mucho tiempo que libros, colectivos o de autoría individual, y ensayos, nuevos o reciclados, sueltos en los medios más o menos especializados o recogidos en números de revista dedicados al tema, vienen circulando no solo en español sino en todos los idiomas occidentales principales sobre la dudosa y cada vez más discutible rol de las Humanidades en un mundo educacional, cultural e intelectual regido por leyes de mercado que convierten al conocimiento en mercancía, a estudiantes en clientes o consumidores y a profesores en comunicadores de fórmulas fácilmente digeribles y aplicables supuestamente a contextos y problemas social o económicamente útiles. Se nota en seguida que título y subtítulo apuntan hacia temas que parecen internos a las Humanidades como disciplina académica e intelectual dentro de un nuevo entorno mediático. Sin embargo, aunque disfrazada en su título, la íntima relación entre estas Humanidades cuestionadas y la política surge casi inmediatamente en las páginas de presentación del compilador del volumen colectivo, Aldo Mazzucchelli, quien, después de establecer la distinción entre "escritura" y "mero letreo" (textos breves de mensajes, tuits e emails destinados a un olvido tan rápido como su borradura), pasa a explicar las bases y principios que orientan no solo las contribuciones del volumen en cuestión sino que también pueden verse como una reafirmación de los propósitos que determinan lo que es en realidad toda una campaña por parte del grupo que constituye Henclopedia en contra de lo que ellos- y tantos otros - ven como la progresiva analfabetización de por lo menos una generación entera de jóvenes uruguayos, mayormente a manos del sistema público de educación, sea al nivel de escuela, liceo o universidad.

Al no molestarse en insistir en las consecuencias de no observar la diferencia básica entre "escritura" y "letreo", Mazzucchelli sostiene que se corre el riesgo de devolver los poderes asociados con la escritura a una privilegiada élite mientras <<a la mayoría se la deja en el letreo, bueno únicamente para la coordinación de las operaciones de sentido común, los acuerdos sobre acciones, el consumo de bienes y servicios >>. Escribir, por lo contrario, es <<un régimen tecnológico asociado a una forma de este en el mundo: no solo un registro del espíritu, sino un tipo de espíritu, registrado>>, de lo cual en parte resulta que <<hay una 'crisis de la educación', y todo el mundo se da cuenta de ella >>. Aún más grave, para Mazzucchelli, <<la historicidad se retrae junto con la letra $>>$ aunque $<<$ sin historicidad, es difícil concebir la política >>, dejando que este sujeto moderno, deshistorizado y despolitizado por encontrarse privado también de las herramientas necesarias para interpretar y producir la escritura, se vea condenado a 'resolver problemas' en un mundo dominado por <<el problema no narrativo por excelencia, el problema de los datos >>. Por lo tanto, las Humanidades en la actualidad se ven obligadas a repensar su 
<<institucionalización histórica . . y y sus implicaciones en relación con cualquier orden o imposición exterior al de la consecuencia del pensar>> (Macchuccelli 2016: 7-10 y 13-14).

Una suerte de anticipo de tales consideraciones se ve en la explicación de Henciclopedia publicada en su portada. El escritor, probablemente el director Amir Hamed, le asegura a sus lectores que se trata de un espacio para <<múltiples >> disciplinas, de la crítica literaria a la antropología, y fenómenos culturales, tanto cultos como populares, siendo <<un medio dedicado a llenar el ciberespacio de cultura desde Uruguay>>, implicando de paso que el mundo de Internet está lleno de trivialidades efímeras que no merecen la descripción <<cultura〉> y que hace falta un país tan chico y periférico como Uruguay para llenar este vacío de productos culturales que puedan actuar de contrapeso a todas las banalidades opacas que se hallan allí: <<Género y estilo son llaves para la percepción de los fenómenos culturales de esta época. Lo que estas rubras no involucren queda para el resto de la cultura, es decir, para las cosas en general > (Henciclopedia, 1999), mostrándose dispuesto a mantener del pasado tradicional dos conceptos no generalmente asociados con la mayor parte de lo que se encuentra en las redes sociales y los sitios del www., aquí relegado al nivel inferior de <<cosas en general >>.

Hamed podía permitirse mayor claridad y precisión unos quince años después, en el prólogo, sintomáticamente titulado <<Incorrecto, claro está>>, al primer número de la revista Interruptor, recopilación en formato impreso de una selección de las muchas y frecuentes columnas virtuales homónimas que se venían publicando en forma digital desde agosto de 2012, mayormente contribuciones individuales de los distintos miembros del grupo de Henciclopedia (Carlos Rehermann, Gustavo Espinosa, el ya mencionado Mazzucchelli y Hamed mismo), con notas ocasionales de otros pensadores y escritores afines como Alma Bolón y Sandino Núnez, por ejemplo. Hamed, mezclando tonos de sátira feroz y manifiesto fuerte, propone a Interruptor como:

una publicación de cultura en su acepción vieja y dura, y en ese sentido, nunca progresista pero siempre libertaria: una publicación convencida de que esa figuratan manoseada como imprescindible, el lector, sigue allí, escarbando páginas, no para encontrar respuestas de autoayuda sino para afilar sus interrogantes; y convencida, también, de que la cultura y la lectura son medicina para el alma (y ciertamente el alma es algo que se activa en cada lectura y no, como algunos pueden llegar a creer, un software obsoleto que se dejó de usar en la Edad Media). Peor aún, una publicación literaria, hecha por literatos (y no por sociólogos, etnólogos, politólogos, ni siquiera por farmacólogos metidos a opinar sobre hechos culturales), persuadida de que si no hay literatura, o escritura fuerte, lo que se disipa es el mundo, ontología que se retira para dejar en escena una nauseante montonera de guarismos, estadísticas, sondeos de opinión y panfletos publicitarios travestidos de doctrina. Una publicación, por si faltaba algo, política, y esto, precisamente, porque se trata de una intervención desentendida de cualquier excusa tecno de corrección política. Una publicación para decirlo de otro modo, dedicada a discutir los asuntos de la polis, lo público, el bien de la república, y olvidada de cualquier tecnificación de los asuntos sociales, eso que algunos proponen como pospolítica y que, como señala Slavoj Zizek, ahoga cualquier discusión (Hamed 2014: 9). 
En estas líneas Hamed reivindica varios conceptos primordiales para la visión del mundo que nos ofrece tanto Henciclopedia como Interruptor. Por tanto que reconoce la libertad individual de los autores de las contribuciones, Hamed enfatiza que la perspectiva crítica sostenida en Interruptor sobre cuestiones de cultura o sociedad es de izquierda pero de una izquierda libertaria, disociada de la diluida centroizquierda frenteamplista implicada en el uso despectivo de la palabra 'progresista' y explicitada en la referencia a Zizek, filósofo marxista también 'incorrecto' que cuestiona, subvierte o invierte un sinnúmero de lugares comunes sagrados de una izquierda socialista tradicional, y rescata elementos importantes de fenómenos históricos supuestamente irrescatables o simplemente innombrables como el estalinismo soviético o el terror revolucionario de la Francia de los 1790s. Además, Hamed elogia lo convencionalmente literario (subrayando todos sus elementos más tradicionales como autor y lector) como espacio privilegiado para cuestionar y analizar, espacio todavía ni neutralizado ni desplazado por plataformas digitalizadas que subrayan las ventajas de lo inmediato pero efímero, de lo mediatizado pero no meditado. Este punto de vista sobre el valor de lo literario tanto de Henciclopedis como de Interruptor está bien resumido en una reseña que hace Carlos Rehermann de la publicación en Argentina en 2013 de la traducción al español de un libro que el crítico literario marxista inglés Raymond Williams había publicado en 1950. Lectura y critica, primer libro de un profesor de la Universidad de Cambridge que también enseñaba clases para el Worker's Education Authority (instituto estatal dedicado a la enseñanza de esos muchos trabajadores británicos que nunca habían terminado secundaria, en gran parte debido a las exigencias y escaseces ocasionadas por la depresión económica de los 1930s y después por la segunda guerra mundial), mostraba cómo leer bien a través del análisis de la crítica literaria mal hecha en los periódicos y revistas de la época (Rehermann 2014). A Williams a veces le tildaban de culturista de izquierda, descripción no del todo ajena a la posición del grupo que saca Henciclopedia, aunque parece justo agregar que Williams tenía bien poco de anarquista o libertario.

Que todo lo anterior baste para comprobar que para Henciclopedia la cuestión de las Humanidades es profunda y obligatoriamente política, pero no porque haya que politizar el contenido sino porque el rol que ha jugado siempre ha sido principalmente político y porque su situación actual exige una reafirmación y una reformulación de ese papel de formación de individuo y ciudadano que, en muchos de los debates contemporáneos, los intereses corporativos o comerciales han querido silenciar o sustituir por consideraciones puramente utilitarias. Como ya hemos visto, Henciclopedia practica una militancia política a favor de restablecer, bajo nuevas circunstancias que requieren nuevas manifestaciones y formas para las Humanidades, su antiguo papel formativo en la sociedad actual.

De allí que Alma Bolón, editora de la segunda entrega de la mencionada colección lengua nueva de $\mathrm{H}$ editores, pueda titular su introducción <<Literatura, mapa sin territorio: en su procura >> y 
comenzarla con esta frase combativa: <<Con ánimo decidido, este volumen aspira a hacer política, para lo que reúne reflexiones en torno al lenguaje, a la escritura, a la literatura, a cierta posibilidad de la verdad > (Bolón 2016: 7), porque es la escritura, definida como cierta condición del lenguaje cuya textura es esencial en la literatura, el factor determinante en circunscribir qué tipo de verdades y bajo qué circunstancias son accesibles a través del lenguaje. Bolón toma el titulo de sus páginas de presentación de un párrafo del texto que cierra el volumen, <<Explicación territorial de la literatura >> de Gustavo Espinosa, donde se examina la literatura desde la perspectiva de escribirla en el llamado 'interior' del Uruguay, abarcando también otras experiencias literarias periféricas:

Creo que en verdad somos [militantes territoriales de infantería de la escritura] no solo porque fabulamos las fronteras miserables de la ciudad letrada, sino - sobre todo - porque, al igual que los escritores que viven en los barrios burgueses, oaquellos que escriben, digamos, sobre Manhattan, o los que hace 2500 años escribieron en Atenas acerca de Argos o de Tebas, oficiamos esa tradición tan escurridiza a las mediaciones conceptuales que hemos dado en llamar literatura (Espinosa 2016: 89).

La referencia a la "ciudad letrada" nos remite inevitablemente al libro póstumo de Ángel Rama, volumen cuya polémica historia posterior limitaciones de espacio nos impiden analizar aquí. Sin embargo, el uso de su título aquí sugiere que ni para Espinosa ni para Henciclopedia el concepto allí referido ha perdido su vigencia, observación subrayado en el título del volumen editado por Bolón: El animal letrado: literatura, verdad, política, el que nos recuerda que es precisamente el ciudadano de tal ciudad cuya existencia ha sido puesto en tela de juicio si no en peligro mortal de desaparecer de su mapa.

\section{HENCICLOPEDIA Y LA ESCRITURA: LOS ARGUMENTOS PRINCIPALES}

Hamed ha publicado lo que puede leerse como una breve fábula sobre esta amenaza inminente. $<<$ O humanidades o nada $>>$, para establecer la imprescindible y urgente necesidad de las Humanidades en nuestro tiempo, busca enseñarnos una analogía cercana o paralelo directo entre la situación geopolítica del mundo occidental del siglo XI, primero del segundo milenio según el calendario cristiano, y la que rige en nuestro siglo XXI, primero del tercero. Hamed compara la invasión del Medio Oriente después de la destrucción de las Torres Gemelas con las Cruzadas que, fundándose en las lecciones del apocalipsis bíblico, aprobara el papa Urbano en 1095, solo siete años después de que en Bolonia <<una agrupación de extranjeros se conforma en grupo de estudiantes, contratando maestros para que les enseñaran las leyes de la ciudad>>, evento que acunó su adopción a mediados del siglo XII de la primera Carta Constituyente que incluye la libertad e independencia académica a nivel terciario, así siendo la primera de las instituciones que conocemos como Universidades. O sea, resume Hamed, para mejor <<interrogar el mundo $>$, el estudiante debía tener una libertad total para perseguir su conocimiento por donde lo llevara 
esa búsqueda (Hamed 2016: 132). El autor completa su analogía y apuntala la pertinencia actual de la moraleja de su fábula en los siguientes términos:

\begin{abstract}
Conviene tener a mano esta breve historia siempre que se escuchen reclamosa la Universidad y, en particular, a su rama más ostensiblemente improductiva,o apragmática, las Humanidades. Para dar cuenta del mundo, y de su Ley, laUniversidad desde un principio debió darle la espalda al dictado de su sociedad,que para empezar dictaba la necesidad del Fin del Mundo, algo que parecenreiterar, hoy día, las tecnologías desentendidas de otra legitimidad que no seasu performativo ..., y un capital hipostasiado en sus finanzas, eso que hoy sellama financiarización, que no es sino el vaciamiento de los recursos del futuro.

. . . Si la Universidad se somete a este vampirismo, si no logra cuestionarlo (algoque solo pueden hacer las Humanidades), estará renunciando a sí, es decir, estará renunciando al mismo mundo que desde hace unos 1000 años viene sosteniendo,justo cuando el mundo, más que nunca, amenaza entregar su renuncia (Hamed2016: 133).
\end{abstract}

Es fácil discrepar con alguna imprecisión o hipérbole en esta analogía. Es difícil, sin embargo, no ver en la vasta mayoría de las universidades de cualquier lado del planeta, cómo las facultades más supuestamente "pragmáticas" se unen para asegurar que, en la distribución de los fondos disponibles, las facultades de humanidades sean perpetuamente los parientes pobres, a veces casi mendicantes, de la familia universitaria. $\mathrm{O}$, por decirlo de otro modo, según las estadísticas que miden estas cosas, en cuanto a horas de clase dadas, resultados de investigación conseguidos o puestos de trabajo postulados con éxito por sus egresados, las facultades de humanidades resultan ser a menudo las facultades más baratas de su institución.

No obstante, es sumamente importante que Hamed y los demás miembros del grupo de Henciclopedia no repitan estas perogrulladas que operan en el campo de los que cuentan los centavos, sino que prefieren con razón plantear sus argumentos según los criterios que emanan de las mismas preocupaciones humanísticas porque, implícitamente, siempre sostienen que, de hecho, no se trata de justificar su lugar en el abanico de disciplinas incluidas en la universidad, sino sencillamente de explicar el rol que siempre ha jugado y que sigue siendo aún no solo deseable sino absolutamente necesario. De aquí que Hamed tenga otra versión más larga y actualizada del argumento de $<<$ O humanidades o nada $>>$.

En $<<$ Lo literario y su certidumbre >>, invocando lo que para Hamed es el nudo de toda la cuestión de las Humanidades, se pregunta; $<<_{i}$ Es posible el humano sin la escritura? >>, y postula, siguiendo al $<<$ hasta ahora irrebatible Jacques Derrida $>>$, que el lenguaje hablado fue eco de <<una escritura que tal vez se olvidó >>, arguyendo después que, aunque los sumerios puedan haber creado $<<$ sus letras para llevar contabilidad>>, el siempre presente suplemento los habría llevado inevitablemente a la poesía: $<<$ Llevar la cuenta no logra alejarse del hacer el cuento, o recuento. El dato, como los pétalos de una flor carnicera, se abre al entresijo de la ficción, del puede ser, del y si acaso > (Hamed 2016a, 73-5). El suplemento derrideano se nutre de los siempre presentes sentidos yacentes que busca en vano suprimir una anhelada pero nunca existente precisión, a la cual a largo plazo terminan suplantando. 
Por tanto, el lenguaje no pertenece nunca al hablante, rasgo que la escritura hace explícito: <<La escritura, y entre sus variantes, más que ninguna la literaria, no solo se sabe alien; tiene como mandamiento dar cuenta de lo ajeno〉>. Más bien, <<eso, precisamente, desde siempre ha sido la función de la literatura: cuestionar, proponer disyuntivas a lo establecido, barbarizar, es decir, enajenar con un tropo >>. Pero no todos están ni dispuestos ni capacitados para recibir en casa a este alien: <<el que replica diferente nuestra lengua nos hace dudar de ella, inaceptable como "casa del ser", según pretendía Heidegger. Su extranjería los fuerza a percibirla, precisamente, como cosa foránea, azarosa, un inquilinato, más bien>>. Pero es exactamente a través de esta enajenamiento que puede emprender su campaña contra $<<$ la mentira de hoy y de mañana . . . :el capitalismo sin freno $>>$, el que con sus agentes $<<$ nos quieren ignorantes, acríticos, dóciles $>>$, por lo cual hacen elogio de la <<oralidad >>, es decir, esas formas lingüísticas que favorecen lo inmediato, lo espontáneo, momentáneo e instantáneo y lo efímero, apropiadas para un mundo regido cada vez más por tecnologías virtuales tan veloces, exigentes y seductoras que amenazan con robarnos el tiempo y las herramientas verbales e intelectuales esenciales para el pensamiento analítico (Hamed 2016a: 76-7 y 83).

Henciclopedia busca fundamentar sus principios y bases no solo en las contribuciones propias (todo el grupo tiene altas calificaciones académicas tanto nacionales como de universidades extranjeras y una variada experiencia como docentes e investigadores universitarios, además de su currículum de escritores literarios) sino también a través de la reproducción o traducción de importantes ensayos o discursos sobre la cuestión del rol actual y futuro de las Humanidades elaborados por distinguidos contribuidores internacionales. Entre estos últimos se destacan los de Jacques Derrida y Hans Ulrich Gumbrecht. El de Derrida, una conferencia pronunciada por primera vez en 1988 en la Universidad de Stanford, lleva en su versión impresa el breve título $<<$ La universidad incondicional $>>$, aunque su mucho más largo título original como conferencia, que da una idea mucho más clara de su contenido, era $<<$ "El provenir de la profesión" o "La universidad sin condición" (gracias a las Humanidades, lo que podría tener lugar mañana) > (puntuación y cursiva en el original). En un planteo que recuerda el de Hamed esbozado arriba, Derrida mantiene un concepto de incondicionalidad que incluye no solo una libertad de enseñar e investigar sino un derecho absoluto de $<<$ decir públicamente todo lo que exigen una investigación, un saber y un pensamiento de la verdad >>. Propone un acto de profesar que es igualmente la práctica de una disciplina y una profesión de fe vocacional dentro de unas <<nuevas Humanidades〉> que combinen <<mundialización〉> y <<humanización〉>. Agudamente consciente de que tal universidad sin condición todavía <<no existe, de hecho, como demasiado bien sabemos $\gg$, la plantea como <<un último lugar de resistencia crítica - y más que crítica - frente a todos los poderes de apropiación dogmáticos e injustos >>. Frente a la capacidad desestabilizadora de la <<nueva "etapa" técnica de la virtualización 
(informatización, numeración, mundialización virtualmente inmediata de la legibilidad, teletrabajo, etc.), Derrida se pregunta no sin cierta evidente angustia: < ¿ ¿Dónde se encuentran hoy el lugar comunitario y el vínculo social de un 'campus' en la época ciberespacial del ordenador, del teletrabajo y de la world wide web? >>. Bajo el paraguas amplio de conceptos de soberanía, libertad, independencia que recuerdan el de la <<democracia por venir >> desarrollado en su libro La política de la amistad (1994), Derrida dedica gran parte de su extensa ponencia a una meditación sobre la interacción de 'trabajo' y 'obra', y termina con una lista de preguntas que recomienda que los oyentes se hagan sobre lo que acaban de escuchar: <<¿Es académico? ¿Es un discurso del saber en las Humanidades o acerca de la Humanidades? ¿Es únicamente saber? ¿Únicamente una profesión de fe performativa? ¿Pertenece al adentro de la universidad? ¿Es filosofía o literatura?, ¿o teatro?>>, cerrando con una frase que es a un mismo tiempo invitación perversa y voz de alerta amistosa: <<Tómense su tiempo pero dense prisa en hacerlo pues no saben lo que les espera > (Derrida 1988, cursivas en el original).

De las dos contribuciones de Gumbrecht accesibles en el archivo de Henciclopedia, la primera es una conferencia pronunciada en Uruguay como invitado de honor en el 150 aniversario de la Universidad de la República en 1999. Titulada <<Milenarismo universitario. Las revoluciones de los medios y el futuro que les queda a las Humanidades >>, la ponencia hace un equilibrio en momentos bastante torpe entre un cronograma europeo y la historia uruguaya y latinoamericana para narrar una crónica de los estudios superiores que se arrastra de una a otra crisis social y epistemológica desde la fundación de las primeras universidades modernas en Alemania a principios del siglo diecinueve. Sin embargo, termina con una evaluación de la pertinencia actual de las Humanidades parecida a la de Derrida. Las Humanidades, sostiene Gumbrecht, junto con otras disciplinas, deben enseñar cómo leer textos tan complejos que no pueden ser reducidos a cualquier significado univocal, y deben resistir cualquier intento de presionarlas a reducir esta complejidad porque de esta base depende el propósito mayor de fomentar las Humanidades hoy en día: <<la defensa, la propagación de la formación individual y de la vivencia - en el sentido definido [de convivencia y experiencia] - es lo que nos queda〉> (Gumbrecht 1999).

En su segunda contribución - no en orden cronológico de primera publicación (1995) pero sí en el de su disponibilidad en español a través de su inclusión en el mencionado volumen colectivo de Mazzucchelli gracias a una traducción hecha especialmente por el editor del compendio -, Gumbrecht se muestra menos optimista acerca del futuro de los estudios literarios, a pesar de la evidente centralidad de la buena literatura y la apreciación de sus valores para el cumplimiento de los fines que acabamos de verle dar a las humanidades en general. Gulbrecht aprecia debidamente la presión ejercida sobre los valores literarios tradicionalmente defendidos en los departamentos de Literatura, haciendo que cualquier intento de $<<$ repensar los estudios literarios $>>$ sea menos un asunto interno que el <<desafío de determinar y 
tomar en cuenta el entorno epistemológico transformado>> en el que <<cualquier desarrollo de la disciplina hacia el futuro tendrá que tener lugar >>. Sin embargo, atrapado entre su pasado europeo y un presente mimado en algunas de las universidades norteamericanas de mayores recursos, Gulbrecht puede terminar solo con una pregunta que evidentemente no sabe contestar: << ¿en qué proyectos futuros, programas, e incluso tal vez disciplinas podemos y debemos invertir lo que hemos aprendido al volvernos y ser investigadores de la literatura?>> (Gulbrecht [1995] 2016: 119 y 125). Claro, el desdichado de Gulbrecht no había tenido la oportunidad de leer a $<<$ O humanidades o nada $>$ y $<<$ Lo literario y su certidumbre>> (Hamed 2016 y 2016a).

Del grupo que saca Henciclopedia el que más se asemeja a Gulbrecht es quizá Mazzucchelli (ambos trabajaron en la Universidad de Stanford), a quien también le interesa la larga historia de las Humanidades aunque la mira desde una perspectiva más local y llega a conclusiones que, aunque a veces similares a las de Gulbrecht, tienen mayor pertinencia a la situación uruguaya. Aquí, descartando por nuestros propósitos las muchas notas más breves que Mazzucchelli ha escrito para la Interruptor virtual, me limitaré a analizar dos ensayos largos, artículos bien meditados que se publicaron en revistas académicas arbitradas antes de ser reproducidas en Henciclopedia. <<El pecado original de las Humanidades>>, recogido en Henciclopedia en tres partes, I,II y III, pero también almacenado allí en forma abreviada en dos partes como <<¿Hay futuro para las Humanidades?>> I y II, se publicó por primera vez en setiembre de 2013 en la Revista Chilena de Literatura. Mazzucchelli enfoca la cuestión del rol contemporáneo de las Humanidades a través de una crítica a un infame o famoso artículo del docente y crítico literario estadounidense Stanley Fish en el New York Times del 6 de enero de 2008, en el cual Fish se preguntaba - y nos preguntaba a nosotros y a sus lectores - < ¿Pueden salvarnos las Humanidades?>>. Fish, después de descartar las justificaciones tradicionales de las Humanidades (por ejemplo, el estar en contacto con lo mejor que los seres humanos han creado en literatura, filosofía, historia, etc., nos ayuda a ser seres moralmente mejores; el goce del saber y de la lectura de lo estéticamente superior es un valor en sí que debe ser transmitido de una generación a otra), llega a la conclusión de que enseñar las Humanidades no sirve realmente ningún propósito social salvo el que pueden sacar del proceso las personas que lo emprenden, y que este valor de lo inútil era un bien supremo (se oyen ecos tanto de Kant como de Oscar Wilde, me parece). Como es de esperar, muchos de los que comentaron su artículo llegaron a la conclusión de que, si así era, no valía dar recursos económicos a tales facultades dedicadas a enseñar lo que los individuos interesados podían hacer por cuenta propia en su tiempo libre, todo lo cual parecía aun más justificado cuando Fish mismo, interrogado por qué continuaba dando clases de literatura, respondía que lo hacía porque le pagaban bien para hacerlo. 
Hasta aquí, bien. Sin embargo, el comentario de Mazzucchelli a esta altura de su ensayo no es enteramente convincente:

\begin{abstract}
Lo que Fish olvida en una postura que a fin de cuentas es cínica, es que si las humanidades no pueden ya casi encontrar significación en una formación del carácter y la personalidad que estuvo claramente en la base del proyecto original, eso es en buena medida porque con la caída exclusivamente en Occidente - de cualquier noción transcendente de verdad, cayó la única base que podría haber permitido que una discusión cualquiera conduzca, en último término, a una convicción firme y transmisible. En parole povere: sin metafísica - o sin fe genuina - no puede haber humanidades. Pues el proyecto original de las humanidadesnunca fue enseñar 'a analizar efectos literarios' por sí, sino como una parte del quehacer universitario cuyo centro estaba en la Wissenschaft - investigación y la práctica de la enseñanza - de materias cuyos contenidos, a comienzos del [siglo] diecinueve, aún se creía orientados y en relación con una verdad mayor y más estable que la mera opinión de los sujetos (Mazzucchelli 2013, I).
\end{abstract}

Aquí, Mazzucchelli parece estar en total desacuerdo no solo con Derrida mismo (para quien crítica era sinónimo de deconstrucción en su <<la universidad sin condición $\gg$, sino también con su colega Hamed y su referencia al <<irrebatible〉> Derrida. A la manera de Vargas Llosa (2010 y 2012), Mazzucchelli parece echarle la culpa de este ocaso de <<cualquier noción trascendente de verdad>> y de la autoridad 'natural' de los que la poseen, a los que trabajan dentro de los variados campos incluidos en las Humanidades. Sin embargo, lo que olvidan Vargas Llosa y (aquí, por lo menos) Mazzucchelli, es que tal eclipse parece ser más bien consecuencia de la progresiva corporativización de las universidades, la conversión del conocimiento en mercancía y la consecuente transformación del estudiante de aprendiz en cliente a quien hay que satisfacer, más la ubicuidad de una nueva tecnología informática que aceleraba este proceso, cuantificando todo hasta el punto de exigir que paulatinamente la lenta pero difícilmente medible acumulación de conocimiento se convirtiera en la muy calificable destreza en el uso de datos específicos pero limitados para resolver problemas aislados aunque muy complejos.

En otro punto de su texto Mazzucchelli se muestra muy consciente de este contexto, citando a un tal Robert Zemsky, quien hace la siguiente <<pregunta que es bastante incómoda aún hoy . . . : "Empresa y mercado han demostrado ser exitosos, ¿por qué razón no pueden operar las universidades más como empresas? ¿Por qué no pueden tener inteligencia de mercado?” $>$ El autor comenta, correctamente a mi de ver, la pregunta de Zemsky es solo “incómoda" si las Humanidades o la academia permiten que se libre la pelea intelectual y filosófica <<en el campo de batalla y según las armas de las corporaciones〉>, lo cual casi seguramente condenará las Humanidades a desaparecer. Hay que tomarlo como un llamado a las armas para que se libre esta guerra en <<el campo de batalla y según las armas de las humanidades〉> mismas (Mazzucchelli 2013, II, cursivas en el original). O sea, la cuestión es cómo resistir esta invasión de este pensamiento económico neoliberal en un campo que lo rechaza visceralmente pero que encuentra difícil esgrimir argumentos que lo puedan rebatir y ganar: <<La gente sigue escribiendo e integrando su escribir a muchas de las nuevas plataformas tecnológicas que van apareciendo. Pero la gente no sigue 
escribiendo y leyendo, mayoritariamente, el mismo tipo de textos que antes, ni estos juegan el mismo rol masivo que jugaban antes $>$. Tales consideraciones conducen a preguntas urgentes y pertinentes para las Humanidades de hoy: <<¿Para qué tipo de lectura y escritura formar al público universitario? . . ¿Cómo es la forma de pensar y relacionarse con el mundo de alguien formado en la lectura de textos, a secas, versos la de alguien predominantemente oral o formado únicamente en el uso de textos breves > . Ha sido la mercantilización de los procesos paralelos de enseñar y aprender lo que, más que cualquier otro fenómeno, ha ido erosionando y distorsionando los papeles de profesor y estudiante, haciendo que los derechos de éste como cliente socaven la autoridad del primero como experimentado asesor de valores epistemológicos. Sin embargo, para Mazzucchelli, el progresivo neoliberalismo de la academia socava el individualismo necesario para el funcionamiento de las humanidades como formación del individuo, proceso negativo agravado por las consecuencias de la <<estrategia deconstructiva, la teoría crítica y otras “epistemologías de la sospecha”>> (Mazzucchelli 2013, III).

No obstante, como ya vimos arriba, Derrida mismo no vio contradicción alguna entre una profesión de fe y la desaparición de todo vínculo confiable entre lenguaje y algún último referente extralingüístico que garantice la verdad de lo escrito o dicho, mientras para Hamed, la literatura es tan importante como siempre (o quizá, más) en un mundo plagado de conflictos bélicos en los cuales los adversarios políticos o religiosos decretan con violencia fundamentalista la desaparición artificial e ideológica del abismo entre lenguaje y verdad. En tal universo extremista que transgrede la condición insoslayable de cualquier lenguaje como constelación de "huellas" en el sentido derrideano, la literatura vuelve a recordarnos la importancia de la retórica como vehículo de convicción y persuasión y de la verdad como consenso provisional y parcial, nunca definitivo y siempre inestable, logrado por la fuerza que pueden tener éstas de convencer, aunque sea solo por cierto período de tiempo. Nunca hay que olvidar que las ecuaciones de Isaac Newton sobre la gravedad y el movimiento de mareas y planetas se consideraron como verdades durante más o menos dos siglos - hasta ser anuladas para siempre por otro lenguaje matemático: el de Albert Einstein. La literatura imaginativa y la filosofía deconstructiva nos pueden ayudar a vivir y convivir en un mundo en que las verdades de todo tipo son cada vez más precarias y menos duraderas, situación que los fundamentalismos, religiosos o/y políticos, solo sirven para disfrazar o esconder.

La segunda de las dos contribuciones de Mazzucchelli que nos ocupan aquí apareció primero en el segundo número de la resucitada Revista de la Facultad de Humanidades y Ciencias de la Educación de 2015 antes de ser seleccionada por el mismo autor para cerrar un año más tarde el ya mencionado volumen colectivo Humanidades Milenio 3, compilado por él mismo. El título mismo, <<Crítica o crematística: cinco aspectos convergentes en la situación actual de las Humanidades $>$, indica hasta qué 
punto este ensayo continúa las preocupaciones ya vistas en el que acabamos de comentar. Los valores inmediatos e pecuniarios comprometen gravemente donde no destruyen completamente el estudio $<<$ desinteresado $>>$ esencial a la práctica seria de las Humanidades, con el resultado ofensivo de que $<<$ el desinterés se entiende como privilegio de unos pocos; el lenguaje completo como patrimonio, de nuevo, de una elite; mientras que la contracara masiva de las humanidades entendidas como ocio creativo, el entretenimiento, es ofrecido como proyecto masivo a precios irrisorios〉> (Mazzucchelli 2016a: 135).

Haciéndose aliado de las legiones conservadoras que condenan el supuesto anti humanismo de las teorías y metodologías postestructuralistas y deconstructivas, sMazzucchelli condena lo que ve como su pseudo ciencia y sus ataques a la <<intencionalidad〉> por ser cómplices en la socavación de los valores humanísticos ya emprendida por los intereses económicos neoliberales y las nuevas tecnologías virtuales (Mazzucchelli 2016a: 137, 139, 145-6), concluyendo en un tono francamente reaccionario que parece ver como la única salvación para las Humanidades en el mundo de hoy, un retorno a algún pasado casi preindustrial tan paradisíaco como el pueblo de los Hobbits en la novela de Tolkien, visualizado en imágenes en las películas de Peter Jackson:

La conservación de la capacidad de jugar va de la mano con la conservación de lacapacidad crítica y la conservación de la estructura de las cuestiones humanas: corresponde al cultivo de la integridad personal al servicio de una ética fiel a lo que revele el pensar. . .

Me parece que la motivación última para la práctica de las Humanidades es una que se ha vuelto casi inconfesable para la conciencia contemporáneo: el amor. . . .

Amor a la épica humana de los que vieron antes d e nosotros (Mazzucchelli 2016a: 149-150).

Mazzucchelli aquí parece unirse con M. H. Abrams, cuyo <<Cómo hacer cosas con textos〉> de 1979 había resucitado y parcialmente traducido para el mismo compendio, donde Abrams titula su sección sobre Derrida <<La ciencia de la ignorancia $>>$ y termina con una lamentación: <<Lo que perdemos es el acceso a la variedad inagotable de la literatura como textos determinantemente significativos por, para y acerca de seres humanos〉> (Abrams [1979] 2016: 49 y 61). Lo que Abrams y, aquí por lo menos, Mazzucchelli no aceptan, o ni pueden ni quieren ver, es que el lenguaje no expresa ni 'la' ni 'una' verdad; no es una ventana transparente a través de la que vemos una imagen exacta de cómo son las cosas, sin hablar de cómo eran. Lo más raro, sin embargo, es que en esta última frase de Abrams hay un buen resumen de lo que es la situación derrideana, y no su refutación. Es correcto decir que los textos son <<determinantemente significativos >> pero sus significados no están determinados de antemano, así que no se puede saber dónde termina la $\langle<$ variedad inagotable $>>$ de ellos, porque no hay acceso a nada fuera del texto (como las intenciones del autor, por ejemplo) que pueda servir de ancla en este cosmos infinito de significados, lecturas e interpretaciones. Lo que sí puede haber, como ya hemos dicho, es una evaluación consensual de alguna 'comunidad interpretativa' (el término de Fish) que puede durar cierto 
período de tiempo hasta que surja otra más convincente, o algún cierre ideológico impuesto desde afuera por alguna autoridad con fuerza suficiente para hacerla valer. Además, tampoco hay que olvidar al inimitable Roland Barthes, quien afirmó implícitamente en una paréntesis de $S / Z$ (1970) que incluso un mismo texto es siempre diferente o ajeno a sí mismo: <<los que olvidan releer [escribió] se obligan a leer en todas partes la misma historia >> (Barthes ([1970]1991: 11). Siempre la cuestión de la diferencia y la repetición: nada es menos idéntico a sí mismo que lo repetido. Es por eso que hasta los clásicos cambian a través de la historia: no son sus autores los que escriben la historia de las literaturas sino nosotros su público lector o nuestros representantes o sucedáneos en la forma de críticos o historiadores literarios. Es en este sentido que todos los autores están muertos: los que realmente querían decir es precisamente lo que no es accesible a través del lenguaje. Por eso, es posible sostener que se entendería mejor la historia de la literatura uruguaya moderna a través de un recuento analítico de las distintas interpretaciones (locales o extranjeras) de un Onetti o una Agustini que a través de un catálogo o una crónica de autores, títulos y fechas. Como bien entiende Hamed y como parece vislumbrar también Mazzucchelli en sus mejores momentos, es solo en el mundo textual post Derrida que la lectura y la escritura adquieren un valor tan grande que justifica pedir recursos económicos suficientes para enseñar cómo hacer las dos de la misma manera que se enseñan las distintas destrezas y capacidades de una materia tan útil y pragmática como, digamos, la medicina.

Es en este contexto que quisiera terminar este ensayo analizando un debate sobre el rol de las Humanidades entre contribuidores a Interruptor o Henciclopedia y Gustavo Remedi, autor de un polémico ensayo sobre el tema (Remedi 2014). Ni el autor del ensayo original ni Mazzucchelli (ver Remedi 2014a y Mazzucchelli 2014) gastan pólvora o tiempo en la lectura errónea que hizo el primero del anterior ensayo del segundo, texto que ya comentamos arriba (Mazzucchelli 2013). Más pertinente es el intercambio de comentarios entre Remedi y Alma Bolón. El título mismo de la primera misiva de Bolón va al nudo del asunto: $<<$ El elitismo de escribir $>>.{ }^{1}$ Refiriéndose a otro debate en las páginas de Ladiaria, Bolón asocia alegaciones de <<academicismo $>>$ y $<<$ elitismo $>>$ con una complicidad nunca cuestionada con políticas de educación tanto superior como de secundaria que enfatizan temas como extensión e inclusión a expensas de un nivel de contenidos más intelectualmente exigente. La autora ve en la veta "latinoamericanista" de Remedi y su apoyo a los estudios culturales una de facto aprobación de políticas que en los hechos han transformado un intento de democratizar la educación en el Uruguay en una masificación de la ignorancia y un desprecio de la capacidad de escribir:

Inquietante época en que se celebra el incremento del número de egresados de carreras profesionales y técnicas como signo de salud democrática, sin parar mientes en la dimensión universitaria - intelectual, letrada, crítica - que esos egresados hayan debido y podido incorporar

\footnotetext{
${ }^{1}$ Es justo aclarar que el que esto suscribe, tiene otro ensayo anterior que toca directamente este tema (Gregory 2013).
} 
durante su paso por la Universidad,a lo sumo sometidos a una suerte de conscripción en "los sectores más vulnerables”. Inquietante época en que se estigmatiza como elitista la tradición escrita (Bolón 2014).

Remedi no tardó en responder a este ataque. <<Lenguas de papel〉>, su réplica a Bolón, reivindicaba tanto su latinoamericanismo y su tercermundismo como su antieurocentrismo: <<Una cosa es el prólogo de Sartre y otra el texto de Fanon>> escribe, recordando la célebre justificación de la violencia revolucionaria escrita por el filósofo francés en su prefacio a Los condenados de la tierra (1961) de Frantz Fanon, argelino nacido en Martinica, y sigue: <<Algo de esto parece haber querido decir Spivak; o García Márquez cuando hablaba del nudo de nuestra soledad>>. La referencia al novelista colombiano recuerda su discurso al recibir el Premio Nobel de Literatura, en el que, invirtiendo las últimas líneas de Cien años de soledad, habla de dar una segunda oportunidad a los condenados a tal destino. Sin embargo, la referencia a Spivak puede ser una bala que le sale a Remedi por la culata. Gayatri Chakravorty Spivak es una filósofa y crítica literaria de la India cuyo ensayo <<¿Pueden hablar los subalternos?>> es una de las piedras fundacionales de los estudios postcoloniales. Sin embargo, Spivak es también la traductora al inglés de uno de los libros más notorios de Jacques Derrida, De la gramatología (1967), y su prefacio de unas ochenta páginas (1974) fue uno de los primeros en inglés dedicados a su pensamiento (ver Derrida 1976). O sea, se podría decir que hace exactamente lo contrario de lo que hace Sartre con Fanon. La subalterna Spivak se apropia del libro del filósofo metropolitano francés, lo traduce a otro idioma colonial, la segunda de dos lenguas imperiales que Spivak ha hecho suyas, y en adelante demuestra para todos cómo la deconstrucción puede ser un arma contra el colonialismo mental y cultural. Spivak va mucho más allá del antieurocentrismo: rompe las fronteras lingüísticas y culturales entre Europa y sus ex colonias, ganando terreno en el campo de batalla del adversario y desde allí (en su caso, la Universidad de Texas) lanzando dardos como quinta columnista desde adentro para afuera. Difícil pensar en un ejemplo mejor de pensamiento <<territorializado y mediatizado por formaciones socioculturales concretas >> (Remedi 2014a).

Además, la situación de Spivak sitúa la escritura en el centro de su quehacer, a pesar de su condición original de subalterna. Remedi hace bien en subrayar que no hay que despreciar los otros medios ni las culturas populares que no dependen de la escritura pero de allí a apoyar la opinión de Martin Leinhard de que el elitismo es <<pensar la oralidad como carencia, y no al revés: la escritura como carencia > es un paso gigantesco. En una cultura oral, la oralidad no puede ser carencia, pero ¿en una cultura escrita, sea la que sea la plataforma que se use para escribir o leer? Adopta la posición anti derrideana de que la escritura deriva en parte de la oralidad pero <<no es ni más ni menos rica o problemática que la oralidad > (Remedi (2014a). No sorprende que en su contrarréplica Bolón arremeta en contra de esta actitud: no tendría sentido despreciar lo oral en culturas orales pero $<<$ lo que sí es 
acuciante es dirimir lo que sucede entre los individuos que no poseen la escritura y quienes sí la poseen en sociedades regidas por la escritura $>>$, como la nuestra, donde <<la enseñanza se erigió sobre la creencia en la superioridad intelectual de la escritura, en su mayor potencia y en su mayor alcance, lo que incluye su poderío de pensarse a sí misma y, a la vez, a su otro >> (Bolón 2014b). Casi seguramente sin desearlo, uno de los epígrafes que Remedi puso a la cabeza de <<Lenguas de papel〉> anticipa esta crítica:

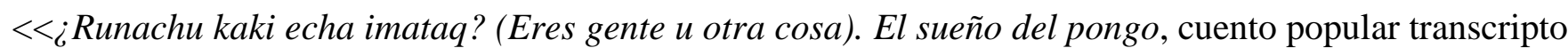
por José María Arguedas > (Remedi, 2014a). Un cuento popular lo suficientemente estable en su forma y contenido como para estar listo para la transcripción ya tendría varias, hasta muchas generaciones de relatores y repetidores. O sea, en términos derrideanos, aun antes de ser oficialmente transcripto, este cuento no escapaba de la textualización, iteración y citación ya asociadas con una cultura escrita y lo que Bolón llamaba su <<poderío〉>. Es en este sentido, si no en otro más históricamente concreto, que la escritura precede al habla.

Es por razones similares o análogas que Bolón rechaza el uso de términos como "Uruguay" o "América Latina" como realidad ineludible o un "aquí, ahora". La dificultad para Bolón que tales frases son simplemente las coordenadas de un <<esquema legislativo-territorial〉> que buscan proferir una legitimidad falsa simplemente porque implícitamente buscan anclar opiniones o afirmaciones en un punto de referencia extra textual que no existe. Por supuesto, esto no es decir que no exista Latinoamérica ni que nosotros no existamos en Uruguay, sino que dentro de un texto tales conceptos resbaladizos, inestables y eminentemente cuestionables pueden funcionar como trampas para desprevenidos o ingenuos. Y es solo la cultura escrita la que puede dar cuenta de este problema y superarlo. Por lo tanto, Bolón puede terminar con unas frases quizás agresivas pero sí definitivamente muy afirmativas:

\begin{abstract}
A fin de cuentas ¿conviene o no que el poder intelectual que se ejerce con la escritura se expanda, se practique, se cultive, se ensalce y sea defendido por quienes aspiramos a la emancipación? Respondo que sí, y en esta medida me resulta inconducente seguir debatiendo al respecto, ya que me resisto a admitir que, en nombre de un "hoy, aquí" que no es más que un señuelo, lleguemos los americanos a renunciar a la fuerza emancipatoria de la escritura, convirtiéndonos, con esta renuncia, en verdugos de nosotros mismos (Bolón 2014b).
\end{abstract}

\title{
3 CONCLUSIÓN: ESCRIBIR, LEER Y EL DEBER CIUDADANO
}

No hay duda de que con el tema de Henciclopedia y las Humanidades estamos ante un fenómeno poco frecuente si no inaudito. Como Mazzucchelli a veces indica, adopta puntos de vista que lo alinean con puntos de vista conservadores sobre la defensa y el mantenimiento de perspectivas muy tradicionales sobre las Humanidades, aunque también emite acercamientos a la cuestión de la escritura que establece muy bien una diferencia absoluta entre lo que llama "letreo" (mensajes que sustituyen la voz hablada en contextos inmediatos y concretos) y escritura, usada para comunicaciones de mayor envergadura, de más 
larga meditación y de referencia más amplia en cuanto a contexto y temática. Sin embargo, lo que realmente llama la atención es la asociación en los artículos y notas de Hamed Y Bolón es la afirmación poco común fuera del contexto puramente filosófico de la conexión íntima entre la fuerza y poder de la escritura en mundo textual regido por una condición que podemos describir como post Derrida o más sucintamente postestructuralista. En este ambiente, una insistencia en lo latinoamericano o lo uruguayo, puede muy fácilmente traducirse en una énfasis sobre lo popular y lo local que. en los intereses de una política de inclusión que parece democrática pero que es solo demótica, suprime o relega contribuciones de alto nivel intelectual o artístico de los continentes metropolitanos a meros esquemas super sofisticados cuyo propósito es esclavizar la mente y la sensibilidad de los jóvenes de países o regiones que todavía no alcanzaron la supuesta sofisticación de los centros super desarrollados. Frente a tal perspectiva, Henciclopedia insiste en la importancia de las tradicionales capacidades de leer y escribir en un planeta regido por la textualidad que emana de tecnologías que frecuentemente buscan desvirtuar y descalificar la importancia del pensamiento analítico que exigen destreza en el uso de un lenguaje complejo, mientras subrayan lo poco que hace falta para ser consumidor y hedonista consumado. Como nos recuerda Amir Hamed, director de Henciclopedia, en su <<Infortunios de la opinión >>: <<cada vez que reivindiquemos nuestro derecho democrático, no olvidemos que este derecho viene ligado a un deber, el deber de cada ciudadano de no opinar sin saber $>\left(\right.$ Hamed 2012). ${ }^{2}$

\footnotetext{
${ }^{2}$ El autor le agradece la oportunidad de reproducir este artículo a los editores de Jornadas de Investigación VII (2017) del Archivo General de la Universidad de la República, Montevideo, donde apareció una versión anterior ligeramente diferente.
} 


\section{BIBLIOGRAFÍA}

Abrams, M. H. ([1979] 2016). <<Cómo hacer cosas con los textos〉> en Mazzucchelli A. (ed.) 2016, pp. 45-61.

Barthes, R. ([1970] 1991). S/Z. Buenos Aires, Siglo XXI, 6ta ed.

Bolón, A. (2014). <<El elitismo de escribir $>>$ Disponible en www.hencicpopedia.org.uy/autores/Alma\%20Bolon/Elelitismodescribir.htm. [Consultado el 16 de agosto de 2017].

Bolón, A. (2014a). <<El verdugo de sí mismo〉>. Disponible en www.henciclopedia.org.uy. [Consultado el 16 de agosto de 2017].

Bolón, A. (2016). <<Literatura, mapa sin territorio: en su procura〉> en Bolón, A. (ed.) 2016: pp. 7-14.

Bolón, A., (ed.) (2016). El animal letrado: literatura, verdad, política. Montevideo, H editores.

Derrida, J. (1976). Of Grammatology. Baltimore, Johns Hopkins University Press.

Derrida, J. (1988). <<La universidad sin condición $>>$ Disponible en http://www.henciclopedia.org.uy/autores/Derrida\%20Jacques/Universidad.htm. [Consultado el 15 de agosto de 2017].

Espinosa, G. (2016). <<Explicación territorial de la literatura〉> en Bolón, A. (ed.), 2016: pp. 85-90.

Gregory, S. (2013). << ¿Experto, intelectual o 'escrilector'?: sobre la dificultad de ser escritor literario hoy en día >. A Contracorriente, Vol. 10, Núm. 2 (Winter): pp. 287-323. [Acceso gratuito en www.ncsu.edu/acontracorriente].

Gumbrecht, H. U. ([1995] 2016). <<Orígenes de los estudios literarios - ¿y su fin?>> en Mazzucchelli, A. (ed.) (2016): pp. 109-125. Traducción del inglés de Mazzucchelli, A.

Gumbrecht, H. U. (1999). <<Milenarismo universitario. Las revoluciones de los medios y el futuro que nos queda $>$. Disponible en http://www.henciclopedia.org.uy/autores/Gumbrecht/Gumbrecht1.htm y http://www.henciclopedia.org.uy/autores/Gumbrecht/Gumbrecht2.htm.

Hamed, A. (2012). <<Infortunios de la opinión〉>. Revista Interruptor, Anno 1, No. 1 (2014), pp. 93-5.

Hamed, A. (2014). <<Incorrecto, claro está>>. Interruptor Revista, Año 1, Núm. 1, abril-junio, pp. 9-11.

Hamed, A. (2016). <<O humanidades o nada〉> en Mazzucchelli, A. (ed.), 2016: pp.127-131.

Hamed, A. (2016a). <<Lo literario y su certidumbre>> en Bolón, A. (ed.), 2016: pp. 73-84.

Henciclopedia (1999). <<¿Qué es H?>>. Henciclopedia. Disponible en

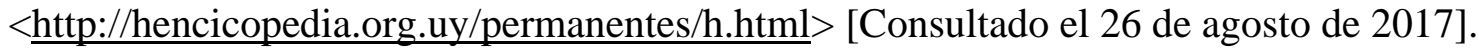

Mazzucchelli, A. (2013). <<El pecado original de las Humanidades I, II y III >>. Disponible en www.henciclopedia.org.uy/autores/Mazzucchelli/Humanidades1.htm 
www.henciclopedia.org.uy/autores/Mazzucchelli/Humanidades2.htm www.henciclopedia.org.uy/autores/Mazzucchelli/Humanidades3.htm. [Consultado el 4 de julio de 2016].

Mazzucchelli, A. (2014) <<Respuesta a Humanidades〉>. Disponible enwww.henciclopedia.org.uy. [Consultado el 16 de agosto de 2017].

Mazzucchelli, A. (2016). <<A modo de introducción: humanidades y letreo. Razón de ser del volumen〉> en Mazzucchelli, A. (ed.), 2016: pp. 7-20.

Mazzucchelli, A. (2016a). <<Crítica o crematística: cinco aspectos convergentes en la situación actual de las Humanidades〉> en Mzzucchelli, A. (ed.), 2016: pp. 133-150. Anteriormente publicado en Revista de la Facultad de Humanidades y Ciencias de la Educación, Año 2, Núm. 2 (2015), pp. 21-32.

Mazzucchelli, A. (ed.) (2016). Humanidades Milenio 3. La naturaleza y el futuro de los seres humanísticos en la era de la virtualidad. Montevideo, H Editores.

Rehermann, C. (2014). <<Mala lectura>>. <www.henciclopedia.org.uy $>$ [Consultado el 26 de noviembre de 2016].

Remedi, G. (2014). <<Elogio de las humanidades y reconstrucción del proyecto humanístico〉>. Revista de la Facultad de Humanidades y Ciencias de la Educación, Año 1, Núm. 1, pp. 69-95.

Remedi, G. (2014a). <<Carta a revista Humanidades $>>$. Disponible ewww.henciclopedia.org.uy. [Consultado el 16 de agosto de 2017].

Remedi, G. (2014b). <<Lenguas de papel>>. Disponible en www.henciclopedia.org.uy. [Consultado el 16 de agosto de 2017].

Vargas Llosa, M. (2010). <<Breve discurso sobre la cultura >>. Letras Libres (revista digital sin paginación), núm. 106, julio. [Consultado el primero de agosto de 2017].

Vargas Llosa, M. (2012). La civilización del espectáculo. Barcelona, Alfaguara. 